\title{
Representando a docência, vou me fazendo professora: uma pesquisa com estagiárias de licenciatura em Música
}

\section{While representing teaching, I myself become a teacher: a research with Music student teachers}

\author{
Cláudia Ribeiro Bellochio*
}

\begin{abstract}
Resumo: O presente artigo decorre de uma pesquisa que teve como objetivo investigar as representações acerca do estágio supervisionado de estudantes em formação acadêmico-profissional do curso de Música da Universidade Federal de Santa Maria (UFSM). Partindo de estudos sobre a formação de professores, estágio supervisionado e educação musical, buscaram-se conhecer e analisar as representações, crenças, ideias e valores dos licenciandos de música em relação ao estágio supervisionado e compreender os processos de gênese e transformação sobre a construção da docência. Os achados indicam que as representações de estágio supervisionado vão sendo modificadas ao longo da formação, e o aspecto central trazido em relação à docência carrega a aspiração positiva de ser um "bom professor" de música, em diferentes espaços educativos. Palavras-chave: Representações. Estágio supervisionado. Docência em música.
\end{abstract}

\begin{abstract}
The present paper derives from a research that aimed to investigate representations about student teaching in the academic-professional formation of the undergraduate course in Music offered by the Universidade Federal de Santa Maria (FUSM). Based on studies concerning teacher's formation, supervised student teaching and musical education, this work aimed to understand and analyze the representations, beliefs, ideas and values of music students in relation to the student teaching model, as well as to understand the processes of genesis and transformation regarding the development of teaching as a whole. The findings indicate that the representations of the supervised student teaching change along the formation and that the central aspect regarding teaching conveys the positive aspiration of being a "good music teacher" in different educational contexts.
\end{abstract}

Keywords: Representations. Student teaching. Music teaching.

\footnotetext{
* Professora da Universidade Federal de Santa Maria. Bolsista Produtividade em Pesquisa do CNPq. E-mail: <claubell@terra.com.br>
} 


\section{Estágio supervisionado: compondo a formação de professores de educação musical}

Estudos acerca do estágio supervisionado (ES) nos cursos de licenciaturas do Brasil e de suas implicações no processo formativo de professores, na vida acadêmica dos licenciandos e na organização das práticas docentes nas escolas de educação básica têm sido ampliados na última década. As investigações, nessa temática, decorrem da preocupação mundial com os processos de formação e ação profissional de professores que, por sua vez, também pretendem melhorar os processos de ensinar e aprender na instituição de formação profissional e na escola de educação básica. (NÓVOA, 1992, 1995; GARCIA, 1995; PACHECO, 1995; IMBERNÓN, 1999; WIELEWICKI, 2005, 2010; dentre outros).

$\mathrm{Na}$ área de educação, produções sobre o estágio supervisionado têm gerado contribuições como as de Pimenta (1995); Lima (2003); Pimenta e Lima (2004); Freitas et al. (2005); Kulcsar (2005); Piconez (2005); Fernandes e Silveira (2007); Wielewicki (2010); Werle (2010); Fernandes (2010). De modo geral, as pesquisas apontam essa etapa da formação acadêmico-profissional como de grande relevância na trajetória formativa para a docência, visto que há neste momento uma aproximação com os contextos de ensinar e aprender e todos os desafios teórico-práticos que neles vão sendo manifestos. Os estudos discutem possibilidades de compreensão e transformação nas ações que constituem o ES como parte do processo formativo profissional do licenciando, como componente curricular. Os autores citados também destacam que o ES, ao ser uma importante etapa na formação profissional, deve ser assumido consistentemente pelo curso e seus professores formadores. Pimenta; Lima (2004, p. 56) enfatizam que "o estágio não se faz por si. Envolve todas as disciplinas de curso de formação, constituindo $m$ verdadeiro e articulado projeto político-pedagógico de formação de professores".

$\mathrm{Na}$ educação musical, as pesquisas sobre a temática também têm sido recorrentes.

Tourinho (1995) realizou um dos primeiros estudos tematizados sobre o ES em música, no qual o destaca como uma etapa da formação profissional em que o estagiário inicia seus aprendizados sobre a sala de aula, adquirindo neste momento habilidades e atitudes profissionais sobre a prática pedagógica. Mateiro (2002a, 2002b) pesquisou sobre o ES a partir de narrativas de estagiárias do curso de Licenciatura em Educação Artística, habilitação em Música da Universidade do Estado de Santa Catarina. Na sequência, Mateiro e Téo (2003) investigaram os planejamentos de ensino de estagiárias durante a realização do ES e revelam "a diversidade de concepções e ações pedagógico-musicais imbricadas na realização do ES” (MATEIRO; TÉO, 2003, p. 94). 
Wille (2004) estudou uma experiência desenvolvida na Licenciatura em Música na Universidade Federal de Pelotas/RS em que constata a necessidade de uma prática pedagógico-musical ao longo da realização do Curso mergulhada na perspectiva de formação de professores como profissionais reflexivos. A autora sublinha que "precisamos, como educadores musicais, rever alguns conceitos relativos ao ensino e à aprendizagem de música dentro da universidade e, consequentemente, nossas práticas educativas" (WILLE, 2004, p. 890).

Bellochio e Beineke $(2005,2007)$ investigaram o ES a partir de oito estudos de caso com estagiários da UFSM/RS e da UDESC/SC tendo como objeto de pesquisa o estudo da construção do conhecimento prático do estagiário do curso de Licenciatura em Música. Alguns resultados apontam para a dificuldade da preparação dos alunos em formação acadêmico-profissional para atuarem na escola pública e a necessidade de aprofundarem a relação universidade-escola, inclusive com inserções mais prolongadas na escola de educação básica. A pesquisa também apontou que a etapa de realização do ES é uma oportunidade ímpar para a reflexão sobre a prática educativa e para a construção dos conhecimentos práticos dos estagiários.

Azevedo (2007, p. 7) buscou entender "como os estagiários de música desenvolvem sua ação pedagógica a partir dos saberes docentes mobilizados e socializados na atividade de estágio". Os resultados de sua tese de doutorado apontam a necessidade de que a formação inicial deve propiciar "condições de aprendizagem docente em que os estagiários exercitem sua capacidade de investigar a sua prática, refletir criticamente sobre sua ação pedagógica e seus saberes e saber argumentar e justificar suas ações” (AZEVEDO, 2007, p. 368).

Subtil (2007) estudou acerca do Estágio Supervisionado da Licenciatura em Música da Universidade Estadual de Ponta Grossa (PR). A pesquisa envolveu análises da relação teoria e prática e também dos relatórios de estágio destacando as primeiras relações que os estudantes têm com a prática de ensino e os desafios do trabalho com seus alunos.

Buchman (2008) em sua dissertação de mestrado pesquisou as concepções que os estagiários têm com relação a este componente curricular. A pesquisa enfocou as concepções de estágio, incluindo a função desempenhada pela orientação à atividade docente na escola, destacando a realização do estágio em duplas e a relação com o ensino na Educação Básica com foco nas experiências dos estagiários.

A partir do contexto da literatura apresentado e da legislação brasileira sobre o estágio supervisionado, percebe-se que as pesquisas, tanto no campo da educação quanto no da educação musical, sobretudo os trabalhos realizados a partir da última década, estão implicadas de modo direto as transformações 
e as orientações decorrentes das novas percepções para a realização dos estágios supervisionados: estágio a partir da segunda metade do curso, aumento expressivo de carga horária, estágio como momento de docência e aproximação à prática profissional, etc. Com isto, "o estágio, em seus espaços formais e não formais e suas implicações pedagógicas e de identidade da profissionalidade não se constitui em um constructo arbitrário" (FERNANDES, 2010, p. 328), requerendo atenção especial e pesquisas que venham a contribuir para uma melhor compreensão da aproximação do licenciando em formação acadêmico-profissional com a docência.

Assim, um dos focos que requer estudos sobre a formação para a educação musical é entender como a docência vai sendo representada ao longo do processo de formação acadêmico-profissional ${ }^{1}$ de graduandos em situação de ES.

A ação de representar parte de "uma ação mental sobre um objeto, sobre um sujeito, constituindo-se como uma forma de colocar-se diante do real" (BELLOCHIO, 2010, p. 212). Representamos o que socialmente elaboramos com o objetivo prático de interpretar situações da realidade cotidiana (ALVESMAZZOTTI, 2008) para nos posicionarmos socialmente em determinada situação. Jodelet (2001) destaca que as representações "são fenômenos sociais complexos sempre ativados e em ação na vida social. Em sua riqueza como fenômeno, descobrimos diversos elementos: informativos, ideológicos, normativos, crenças, valores, atitudes, opiniões, imagens, etc." (JODELET, 2001, p. 21).

Ao representar a docência, as licenciandas revelam a complexidade desta ação, visto que as crenças e valores não são imóveis e refratárias, articulando-se intensamente a "elementos afetivos, mentais e sociais, ao lado da cognição, da linguagem e da comunicação” (ARRUDA, 2002, p. 138).

Neste processo, as relações entre conhecimento científico e senso comum vão modificando as representações de docência e edificando a formação de professor, em um constante processo de transformações.

Outro elemento importante decorre do fato de que, no jogo do ES, entre ser aluno e ser professor, transformações com relação ao que está implicado no que se ensina e nos modos pelos quais se vê ensinado vão emergindo e, ao mesmo tempo em que constroem valores e crenças, estas vão sendo modificadas e reconstruídas. Assim, ao longo da graduação, as representações dos licenciandos em música no ES vão sendo constituídas como indicativos de como eles significam a docência no processo de sua formação acadêmico-profissional e vão transformando os seus sistemas de referência em relação a ser professor.

\footnotetext{
${ }^{1}$ O conceito de formação acadêmico-profissional (DINIZ-PEREIRA, 2008) é tomado para referir "a etapa da formação que acontece no interior das instituições de ensino superior" (ibid., p. 255), já que, no processo formativo docente, é preciso considerar que, em etapas anteriores à formação inicial em instituições próprias, muitos conhecimentos já foram internalizados e constituem-se em lastros sobre os quais vão sendo montados outros saberes e modos de ação profissional do professor.
} 
As pesquisas sobre a formação de professores, de modo especial acerca da socialização pré-profissional dos professores, como apontam Tardif e Raymond (2003), contribuem para a compreensão da ação de representação da docência. As referidas pesquisas debruçam-se nos estudos das experiências pré-profissionais, de modo que os autores consideram que "uma boa parte do que os professores sabem sobre o ensino, sobre os papéis do professor e sobre como ensinar provém de sua história de vida, principalmente de sua socialização enquanto alunos" (TARDIF; RAYMOND, 2000, p. 5). A docência acaba por constituir-se pela fusão das formas vividas e internalizadas, dentro e fora do espaço de formação profissional. Nesse quadro, põe-se a questão do conhecimento internalizado, trazido/compreendido/representado pelo estagiário e sua relação com o ensino que é "categoria fundante, a ser produzido e trabalhado na formação de professores, como em uma teia de relações histórico-culturais, políticas, epistemológicas, pedagógica e éticas" (FERNANDES; SILVEIRA, 2007, p. 2, grifos das autoras).

\section{A pesquisa}

A pesquisa ora apresentada ${ }^{2}$, focalizada nas representações acerca de ES de estudantes da licenciatura em música, também está associada à implementação das políticas educacionais brasileiras, de modo especial as Diretrizes Curriculares para Formação de Professores da Educação Básica CNE 1/2002 e CNE 2/2002, que completam sua primeira década de existência. As Diretrizes significaram um marco nas políticas de formação de professores no país, colocando o estudante em ampla relação com o espaço de seu futuro trabalho profissional, quer seja, a escola e outros espaços educativos.

Passados dez anos, no entanto, questiona-se: em que o aumento expressivo de carga horária para ES modificou a formação de professores? Como o licenciando, em particular o estagiário, percebe e se relaciona com ES ao longo da realização do curso? Quais os significados sobre o ES que o estagiário possui em diferentes etapas do curso? Que valores o licenciando atribui ao estágio e como se modificam ao longo do curso, em especial, ao longo do ES? Quais as crenças, os valores e as atitudes em torno do ES que vão sendo construídos ao longo do curso de formação acadêmico-profissional de professores?

Tendo como referência alguns cenários já produzidos com relação ao ES, as políticas educacionais e as situações vivenciadas junto ao curso de Música licenciatura da Universidade Federal de Santa Maria (UFSM), é que a presente pesquisa foi desenvolvida com o objetivo de investigar representações sobre o estágio supervisionado de licenciandos de música (UFSM), em diferentes etapas

\footnotetext{
${ }^{2} \mathrm{~A}$ pesquisa foi apoiada pelo CNPQ através de bolsa Produtividade em Pesquisa (PQ) e de bolsas de iniciação científica do CNPQ-UFSM e FAPERGS/RS.
} 
do curso, buscando-se conhecer e analisar suas ideias, valores e práticas em relação ao ES e também compreender alguns processos de gênese e transformação sobre a construção da docência.

Assim, a investigação apresentada resulta da necessidade de se compreender, com mais profundidade, a relação longitudinal que os licenciandos do curso de música estabelecem com a docência, sobretudo no momento de formação acadêmico-profissional, no qual estão submersos em proposições curriculares do curso, realizam atividades de estágio supervisionado na escola de educação básica e participam de outras atividades formativas, curriculares e não curriculares que se adicionam e potencializam o processo formativo de ser professor.

Um primeiro destaque deriva justamente desta relação entre os estagiários e a docência desenvolvida no ES. A complexidade formativa tem se revelado em meio ao processo de constituição para a docência, visto que as atribuições e as exigências do curso e da escola que recebe os estudantes são intensas e de naturezas diferentes. Como professora atuante em disciplina de ES há duas décadas, percebemos que, de um lado tem-se o curso e sua estruturação curricular com disciplinas que, via de regra, não dialogam muito entre si e determinam ao estudante uma sobrecarga de atividades disciplinares, de outro, a construção de uma postura de ensinar (e aprender) na escola que acaba sendo construída entre atribuições de ser professor e "comportar-se" como aluno. É neste emaranhado de atribuições para a formação acadêmico-profissional que a docência vai sendo pensada, representada, estruturada, desestabilizada, construída e reconstruída.

Com uma abordagem qualitativa (BOGDAN; BIKLEN, 1994; PACHECO, 1995; SPINK; MENINEGON, 2000), a pesquisa foi desenvolvida com estagiárias da UFSM, entre os anos de 2008 a $2010^{3}$. Nesta instituição, desde 2005, o curso de Música tem realizado, a partir do $5^{\circ}$ semestre, final da primeira metade do curso de licenciatura, atividades curriculares de ES que somam 410 horas, modificando a carga horária desta disciplina que, anterior à Resolução 02/2002, era de 90 horas.

A investigação teve três fases de coleta e análise de dados e contou com a realização de entrevistas como instrumentos da pesquisa. As entrevistas ocorreram em dois momentos: um com entrevista semiestruturada (ESE) individual e outro com entrevista grupal (EG). Em todas as fases, foram realizadas ESE e EG.

O número de estagiários participantes da pesquisa eram seis, mas, devido à desistência do curso por alguns e o abandono da disciplina de ES por outros, o grupo terminou com três estagiárias, nomeadas, ficticiamente, como Andreia,

\footnotetext{
${ }^{3}$ A pesquisa foi desenvolvida como uma ação do grupo FAPEM: Formação, Ação e Pesquisa em Educação Musical. Participaram, como bolsistas, os acadêmicos: Zelmielen Adornes de Souza (PIBIC/CNPQ 20092010); Jeimely Heep (BIC/FAPERGS 2008-2010); Daniel Stringini da Rosa (BIC/FAPERGS 2010) e Douglas Duarte (PIBIC/CNPQ 2008).
} 
Luiza e Natália. Como o objetivo não estava centrado na quantidade de informações, mas na compreensão das representações e suas transformações acerca do ES/docência, este fato - a redução no grupo de estagiários - não inviabilizou o estudo.

A primeira fase (2008/09) da pesquisa foi realizada no momento em que as alunas não estavam inseridas no contexto do ES. A segunda fase $(2009 / 10)$ deu-se quando já estavam cursando a disciplina de ES I e II, correspondendo ao quinto e sexto semestres do curso. A terceira fase (2010) correspondeu ao período no qual as estagiárias cursavam o sétimo e o oitavo semestre do curso de Música - Licenciatura Plena, fazendo a disciplina de ES III e IV. Para a realização total da pesquisa, seguiu-se um roteiro de ESE organizado em cinco grandes temas: (a) trajetória de formação musical; (b) trajetória com o ensino; (c) trajetória com o ensino de música; (d) ideias, valores, percepções e práticas sobre o ES; (e) ideias, valores, percepções e práticas no $\mathrm{ES}^{4}$.

O roteiro das EG teve mobilidade e foi sendo construído a partir de destaques resultantes dos achados e análises das ESE de cada fase. As análises, realizadas a partir das falas e com o suporte da revisão de literatura realizada, geraram motes dialogais para as EG. Na fase 1, a EG teve como orientação a discussão acerca de: 1) Como aluno, o que aprendo para ser professor; 2) Estágio é para colocar em prática o que aprendeu; 3) Supervisão de estágio é dar aula com alguém te observando; 4) Estágio para licenciatura é como percepção para o bacharelado; 4) O que é teoria e o que é prática?

$\mathrm{Na}$ fase 2 da EG, o diálogo foi orientado pelas questões: 1) Por que o aprendizado de flauta-doce e do canto coral foi destacado no contexto formativo da licenciatura em Música? 2) Como as oficinas do Laboratório de Educação Musical (LEM-CE) se somam na construção de sua forma de ensinar no estágio? ${ }^{5}$ 3) O que as proposições metodológicas significam no contexto de elaboração de sua prática como professor? 4) O que é "tornar-se crítico" no curso de licenciatura e por que são referidas dicotomias na proposta curricular do curso? 5) Como o estágio potencializa a construção da sua identidade docente? 6) Como são percebidas suas mudanças com relação a ser professor ao longo da realização dos estágios?

\footnotetext{
${ }^{4}$ Com relação aos itens (d) e (e), o sobre refere-se ao que expressavam sem imersão em práticas de ES e o no refere-se ao que diziam quando imersas na docência em atividade de ES.

${ }^{5}$ O LEM é um espaço no Centro de Educação no qual são desenvolvidas atividades de ensino, pesquisa e extensão com foco em educação musical. No LEM, existe um programa de extensão denominado "Programa LEM: Tocar e Cantar" que, desde 2002, estabelece relações formativas compartilhadas entre alunos da Licenciatura em Música e da Pedagogia, congregando ainda acadêmicos de outras licenciaturas. O objetivo central é promover um estreitamento entre atividades musicais e pedagógico-musicais no processo de formação inicial de professores que, em sua ação futura, utilizarão a música em suas práticas de docência. (BELLOCHIO; GARBOSA, 2010).
} 
$\mathrm{Na}$ fase 3 das EG, os pontos discutidos pelo grupo tiveram como mote: 1) O que é licenciatura? Hoje, como vocês percebem a docência em música? 2) O que é ser professor no contexto do curso que tem disciplinas paralelamente à realização do estágio? 3) Como vocês se veem como professoras e como alunas? 4) O que é "andar sozinha"? Como "eu mesma aprendo"? 5) Por que, na fase final de estágio, vocês passaram a somar Estágio Supervisionado e Práticas Educativas como momentos de relevância de "ser professora"? 6) Em algum momento das entrevistas, o ser professor no estágio trazia um modelo de professor citado por vocês. Agora, o modelo é tomado como "o de vocês mesmas". 7) Como vocês, que vêm de diferentes cidades, enxergam o campo Estágio/escola em Santa Maria? Em que isto se confronta ou soma à formação docente? 8) Vocês poderiam falar um pouco sobre o que, inicialmente, pensavam ser Estágio Supervisionado e o que, hoje, esse espaço de docência se constituiu? 9) O que foi ensinar música no Estágio Supervisionado? No processo de EG, destaca-se o aumento de questões e de elaboração de narrativas acerca do ES e da docência pelas estudantes entrevistadas.

O processo de coleta de dados foi gravado com o auxílio de um aparelho de MP4. As entrevistas foram transcritas, gerando um Caderno de Entrevista (CE) para cada fase da pesquisa. A cada fase, após esses procedimentos, as entrevistas eram encaminhadas às estagiárias para que acrescentassem ou corrigissem alguma informação que pudesse apresentar distorções. A análise de cada fase, bem como a transversalização dos dados, foi feita de acordo com a técnica de análise de conteúdo constituída pelas três etapas propostas por Bardin (1977): pré-análise, exploração do material e tratamento dos resultados e interpretação. Assim sendo, na primeira fase, após a transcrição das entrevistas, o material foi lido e discutido por parte do grupo de pesquisa (FAPEM). A seguir, através da exploração da leitura das entrevistas das estagiárias, foram observadas suas crenças e os seus valores com relação ao estágio/docência/ser professor. Cada fase foi analisada individualmente e gerou um relatório parcial. Finalmente, com base na combinação dos achados das ESE e EG, em cada fase, fez-se uma análise interpretativa parcial. Ao final, os dados das três fases foram estudados em conjunto.

\section{Os achados: representando o estágio supervisionado/docência/ser professor}

Para fins de organização do texto, serão trazidas partes das três fases da pesquisa (Fase 1, Fase 2 e Fase 3), com dados decorrentes das ESE e da EG. Neste contexto é que foram constatadas as primeiras significações de ES para as licenciandas e as transformações com relação à docência no ES. Num primeiro 
momento da pesquisa, com as estagiárias ainda não inseridas no ES, suas percepções são edificadas no somatório de vivências e experiências internalizadas, desde a infância, com a música, com os professores, com a escola, com o ensino, etc., nas quais se configuram imagens de ser professor e de aula de música. Essas imagens internalizadas e contadas são utilizadas para construir o significado do ES e, portanto, de docência - atividade profissional do professor.

Um ponto a mencionar é que todas optaram pelo curso de licenciatura em Música, mas não pensavam em se formar professoras. $\mathrm{O}$ que as levou ao curso compõe-se de diversos motivos, dentre os quais cursar disciplinas do Bacharelado $^{6}$, o que seria a opção primeira, para formar-se "músico profissional". Percebe-se que entraram na universidade desconhecendo o que era um curso de licenciatura. No entanto, na análise referente à primeira fase da pesquisa, ao longo dos quatro semestres já cursados, esse quadro foi sendo transformado, e as representações sobre licenciatura/ser professor começaram a ser modificadas. As estagiárias relatam que na licenciatura estão desenvolvendo conhecimentos e tendo vivências que colocaram em dúvida seus objetivos e percepções iniciais de entrada no curso.

$\mathrm{Na}$ Fase 1 da pesquisa, percebe-se que as estudantes não elaboram conhecimentos acerca de quais os desafios que encontrarão na realização do ES, o qual está ainda distante de suas preocupações. Foi comum ouvir que as principais fontes acerca do que é ES, até o terceiro semestre do curso, são de conversas com colegas que já estão no estágio ou já passaram por ele. Assim, uma primeira interpretação, que se pode lançar, é o fato de que no curso, nos primeiros semestres, não se está refletindo sobre ser professor, no espaço da matriz curricular, objeto da certificação que este aluno receberá quando formado. Fica percebida uma matriz curricular em ação com "base epistemológica da racionalidade técnica" (PEREZ GOMEZ, 1992), com um currículo que se inicia por disciplinas teóricas e é sequenciado por disciplinas pedagógicas e de prática na escola, dentre as quais o ES. Por certo, as disciplinas estão trabalhando conhecimentos musicais necessários ao professor de música, mas não estão alargando/inter-relacionando estes conhecimentos com conhecimentos pedagógicos, com o espaço educativo e com os saberes docentes. Certamente esse horizonte formativo necessita ser alargado em sua matriz constituinte como têm defendido Pimenta (1995), Pimenta e Lima (2004), Bellochio e Beineke (2005, 2007), Bellochio (2010).

As estagiárias participantes da pesquisa têm práticas docentes de diferentes naturezas: ministram aulas individuais em escola de música ou em casa, trabalham com educação musical na educação infantil, atuam em projetos

\footnotetext{
${ }^{6} \mathrm{O}$ curso de Música-licenciatura e o de Música-bacharelado têm algumas disciplinas comuns na UFSM, sobretudo nos primeiros semestres.
} 
sociais e de extensão da UFSM e também desenvolvem ensino em grupo. Uma estagiária, no início da pesquisa, tinha experiência docente em escola de educação básica; as outras duas, com aulas particulares de música. Com relação a este dado, salienta-se que as licenciandas têm práticas de ensino desenvolvidas principalmente através de aulas particulares nas quais a música é conhecimento mediador da ação educativa. Esta natureza prática de ensinar diferencia-se da grande maioria de outras licenciaturas, já que, por exemplo, dificilmente um licenciando em geografia terá tido prática de ensinar geografia antes do início de seu curso. O que fica destacado é que a docência anterior e paralela no curso de licenciatura de Música constitui representações comuns sobre ensinar.

Um ponto sublinhado pelas licenciandas, nas ESE, diz respeito às referências de professores que tiveram como alunas na escola e em escolas de música. Segundo Luíza, na EG 1, "a gente convive tanto tempo sendo aluno que monta uma ideia de ser professor".

Essas referências pré-formação acadêmico-profissional, internalizadas pelo sentido que lhes atravessou na experiência como aluna, como expressaram Tardif e Raymond (2003), influenciam em suas práticas como professoras e configuram-se em ideias, crenças, valores que têm a respeito do professor de música, criando lastros para a compreensão de docência no ES.

Um ponto de referencia musical era minha professora. Eu comecei ensinando exatamente como ela me ensinava, primeiro eu comecei ensinando um pouquinho de teoria [...] começando ritmo e tocando, bem simples. (ANDRÉIA, CE I - ESE/2008, p. 40).

As referências pré-formação de prática como professora que estão sendo referidas não se caracterizam, necessariamente, como sendo "a prática como imitação de modelos", no sentido de uma concepção na qual "a realidade do ensino é imutável e os alunos que frequentam a escola também o são" (PIMENTA; LIMA, 2004, p. 36). A crença é a de que, se aprenderam música um dia, esse processo poderá ser trazido como uma forma de ensinar, mas não deixando de levar em conta a dinamicidade que constitui o contexto da educação musical escolar, sobretudo em questões que estão imbricadas na utilização de repertórios musicais, ponto que é marcante e caro nas práticas de ensino de música.

Outra crença, trazida nas primeiras concepções das licenciandas, remete à ideia de que o curso as "alimentará" com todos os conhecimentos necessários ao ES, suprindo as possíveis necessidades da futura profissão.

[...] para mim o estágio supervisionado vai ser aquilo que vai demonstrar realmente o que eu vou ter que trabalhar. [...] Vai me dar todas as ferramentas para seguir minha carreira depois de formada. (NATÁLIA, CE I - ESE/2008, p. 11). 
Fica evidente, na fala da Natália, o quanto existe a noção do estágio como o motor de uma engrenagem, ou seja, existem peças - as disciplinas - que, ao serem acionadas, farão o motor funcionar - o estágio. Essa relação está próxima à ideia da ciência moderna, que visa fornecer instrumentos certos para uma ação profissional efetiva, desconsiderando todo o suporte social, cultural, filosófico que está imbricado nas relações educativas. O estágio é tomado, neste contexto, como uma disciplina prática de coroação para a docência, até mesmo redentora e salvacionista do curso.

Essa relação teoria e prática apresenta-se como um problema ainda não resolvido em nossa tradição filosófica, epistemológica e pedagógica. A teoria vista na ótica da marca cognitiva instrumental traz como representação a idéia de que a teoria se comprova na prática, condicionando uma visão de que a teoria antecede a prática e, que esta, aplica soluções trazidas pela teoria em movimentos de padrões universais, descontextualizados, com modelos que reduzem a complexidade do mundo da vida e do trabalho. (FERNANDES; SILVEIRA, 2007, p. 4)

Esse valor atributivo não pode ser tomado como orientação, já que todo o processo formativo exige teorização, imersão, construção de conhecimentos e experiências ricas e vivas que se enredam no sujeito, no mundo da vida, a ponto de que ocorram internalizações. Como situam Pimenta e Lima (2004), estágio é teoria e prática, e não um ou outro.

Posto isto, não é o estágio como uma disciplina que constitui a docência. Nesta compreensão é preciso mergulhar nas intencionalidades e envolvimentos do ES com a prática social do espaço educativo, entendendo-se ES como um conjunto de ações formativas do curso e dos espaços educativos (destes entre si), encharcadas em experiências que impulsionam internalizações que, aos poucos, possam ir sendo mobilizadas como um repertório de saberes profissionais.

É preciso salientar que a prática de ensino sob a forma de estágio curricular supervisionado é, tanto quanto qualquer outro componente curricular, uma atividade de aprendizagem e, nesse sentido, talvez seja mais preciso situála não como um espaço de mera aplicação de conhecimentos previamente aprendidos, mas sobretudo como um espaço essencialmente de aprendizagem. (WIELEWICKI, 2010, p. 35).

Desse modo, observa-se que, nesta primeira entrevista, as licenciandas estavam atribuindo valores ao ES no contexto da formação acadêmico-profissional a partir de um conjunto de referências decorrentes de internalizações acerca de ser professor, advindas de suas trajetórias de vida como estudantes. Com essas referências compunham o quadro explicativo das representações sobre o ES, marcando em muito as relações com sua trajetória de vida pessoal, como já apontado por Nóvoa (1992); Pimenta e Lima (2004) e outros. 
$\mathrm{Na}$ entrevista grupal, ao exporem sobre o que estavam aprendendo e construindo para ser professor, enfocaram, novamente, as referências, os modelos do bom e mau professor.

Eu acho que a nossa referência vem desde a educação infantil. Até estava comentando isso na aula de estágio. O que é aquele conceito de um bom professor, ou um professor que te marcou de forma positiva ou negativa? Então, eu acho que vem dai a nossa referência até hoje, dos nossos professores. Eu queria ser um professor como esse. O que en gosto da aula dele ou o que não me chama tanta atenção? Porque eu não estou gostando dessa aula? O que esse professor está fazendo que eu não faria ou faria? Acho que é a questão da observação, de a gente conviver tanto tempo sendo aluno que a gente monta uma idéia de professor. $O$ professor que a gente gostaria de ser! (LUÍZA, CE I - EG/2009, p. 1).

Assim como Luíza expressou, a referência tem um papel muito importante na construção do professor que eles querem ser e, a partir do qual, segundo Natália, "vai formar a nossa personalidade, da qual nós falamos, como professor" (CE I EG/2009, p. 1). Sobre a visão de que o estágio é para colocar em prática o que foi aprendido, as licenciandas demonstraram um ponto diferente daquele que havia sido trazido anteriormente, transformando a ideia de ES. Na EG, comentaram que ES "não é só colocar em prática, porque no próprio estágio a gente vai aprender muito [...]. A gente vai entender o que a gente estava vendo na prática, então vai estar mais aprendendo do que colocando em prática” (ANDRÉIA, CE I - EG/2009, p. 2).

Assim posto, percebe-se que as licenciandas não estão vendo o estágio apenas como o momento de colocar em prática a teoria aprendida nos primeiros dois anos de curso mas também como um espaço de aprendizagem e de construção de conhecimentos, no qual o supervisor tem a função de orientação, como é constatado na fala de Luíza: "Aqui a gente está podendo praticar a docência com uma professora te orientando, te ajudando nas dificuldades" (CE I - EG/2009, p. 3).

Observaram-se, nos diálogos estabelecidos entre as licenciandas, algumas mudanças na forma como estão significando o ES, visto que, no momento desta entrevista, já haviam começado a cursar a disciplina de ES I, na qual estavam sendo problematizadas questões referentes à prática docente. A partir das categorias emergidas nas entrevistas da Fase 1 da pesquisa, percebeu-se que as vivências musicais e as experiências, tanto com o ensino em geral e como no ensino de música, seja como aluno ou professor, são formadoras das ideias, percepções, valores, crenças, opiniões e imagens do que para elas significa estágio supervisionado em Música, ou seja, de como alunas de $4^{\circ}$ semestre representam o ES.

Dessa forma, as representações remetem a bons professores que as estudantes tiveram, o que traz uma forte indicação de um provável "modelo" profissional. Esta fase foi muito rica para os processos de compreensão e análise das transformações das representações das estagiárias que haviam sido entrevistadas 
na primeira fase. Estando em ação educacional no contexto da escola e em outros espaços educativos, suas relações com a docência mudaram substancialmente. Os destaques abordados enfocam a persistência de algumas ideias de "aplicar na prática a teoria" e "seguir um modelo de professor". $\mathrm{Na}$ segunda fase das entrevistas, realizadas no ano de 2009, quando as estudantes já estavam em ES, que se efetivou em turmas de educação infantil, outras crenças e valores com relação a ser professor começaram a ser destacadas.

A gente não é só professor de música. Ai que a gente percebe que vai ser o professor-psicólogo, o professor pai-mãe... Tem várias funcões. (NATÁLIA, CE II - ESE/2009).

Nós vamos ser responsáveis por uma parte da formação delas [crianças] e é um grande compromisso. (ANDRÉIA, CE II - ESE/2009).

Estou aprendendo muito mais sendo professora do que como aluna do curso. (LUÍZA, CE II - ESE/2009).

O valor atribuído ao ES neste momento, em decorrência do desenvolvimento do estágio em música na escola de educação infantil, em imersão no contexto da infância, trouxe, para as estagiárias, a necessidade de pensar o professor da infância pequena vinculado ao profissional que tem como ação profissional cuidar e educar. Posto isto, valores que, por vezes, podem passar despercebidos no contexto formativo do trabalho docente são entendidos como valores necessários para a sua realização. Enfatiza-se assim a ideia de que "o professor aprende com a própria prática, na medida em que toma consciência de suas ações e reflete a respeito delas e de seus efeitos sobre os alunos, a escola e ele mesmo" (BRAÚNA, 2011, p. 15.356). Pimenta e Lima (2004, p. 45) enfatizam que o estágio como uma aproximação à realidade terá sentido com "envolvimento e intencionalidade", o que se traduz como produção de conhecimentos na docência. Com este entendimento, destaca-se que "é preciso que os professores orientadores de estágios procedam, no coletivo, junto a seus pares e alunos, a essa apropriação da realidade, para analisá-la e questioná-la criticamente, à luz de teorias" (PIMENTA; LIMA, 2004, p. 45).

Outro achado da pesquisa diz respeito às práticas de ensinar música fora do espaço do curso, o que, como já mencionado, é comum entre estudantes de música.

Eu trabalhei na creche. Aula de flauta eu dei para uma aluna da Pedagogia. Eu dei aula de flauta para a menina que morava comigo. Violão eu dava aula para um amigo meu. E aqui no LEM estou ensinando. Tu tens que estar bem, assim, segura do que você vai fazer, porque em casa é uma coisa. Chegar à frente, por mais que se é regente... e se eu errar? e quando está a professora, pior ainda (risos). (NATÁLIA, CE - ESE 2/2009).

Para meu irmão. Ele me pediu para ensinar técnica vocal para ele. Dei aula particular de piano para o meu namorado. (ANDREIA, CE - ESE 2/2009). 
Já trabalhei com algumas oficinas, já trabalhei auxiliando até colegas em alguns momentos, e agora, aqui no LEM. A gente vê a evolução. Até os meus alunos aqui, eu tenho me surpreendido com eles por que eles não sabiam ler nada. É bem satisfatório ver que o processo. (LUIZA, CE - ESE 2/2009).

As imersões em situação de docência, fora do contexto do ES e das práticas educativas que são obrigatórias no curso, também criam referências importantes sobre ensinar. Os momentos nos quais as estagiárias estão ensinando e buscando formas de melhorar o seu trabalho pedagógico, certamente, fazem a diferença em seu processo de construção profissional.

No momento da entrevista, também foram percebidas transformações com relação a como as estagiárias estavam valorando o ES naquele momento. Assim, expressaram que

Eu acho que esse estágio, as aulas que temos tido até agora, nos prepararam bem para esse meio em que a gente vai 'aplicar' mesmo. Antes a gente tinha aquela ideia: Vai entrar no estágio I na primeira semana de aula. Não tem ideia do real que é. No curso você vai ter que se preparar, vai ter que pensar no que vai dar, né? Que crianças que eu vou ter. (NATÁLIA, CE - ESE 2/2009).

Estágio é bem pra gente discutir como dar aula, todas as questões que envolvem a sala de aula, a escola. É essencial. Talvez a disciplina que mais contribua é de ES por que é a que mais prepara para o que a gente vai ser. (ANDRÉIA, CE - ESE 2/2009).

O estágio é esse momento, essa oportunidade que tem mais prática pra gente estar entendendo tudo o que a gente lê, tudo o que a gente discute aqui e poder relacionar isso. Essa questão da teoria e da prática que a gente sempre fala. Como a gente vê agora a importância disso. É um bom momento até para o aluno da licenciatura ver se é realmente com isso que ele vai querer trabalbar. Como ele tem acesso a diversas turmas, eu acho isso importante. No todo, eu acho que é um dos momentos mais importantes no que se refere à licenciatura mesmo, à parte prática, que é ali que tu vais estar dando aula, enfrentando os desafios, entendendo como vai ser o cotidiano. (LUÍZA, CE - ESE 2/2009).

As licenciandas enfatizaram a questão da dicotomia presente no curso de licenciatura em Música. "Até a gente entrar no estágio, é muito separado. Não sei se é por que as outras disciplinas não nos preparam para ser professora, mas parece que fica assim: dois anos tu fazes uma coisa e a partir de agora, tu vai fazer outra" (NATÁLIA, CE II ESE/2009, p. 10).

Natália também comenta sobre a importância de que o ES fosse tratado desde o início do curso, "mais focalizado para tu entrares no estágio e já saber o que tu vais fazer" (CE II - ESE/2009, p. 13). Esta ideia é compartilhada por Buchmann (2008, p. 129) que salienta que "o estágio supervisionado deve ser uma preocupação de todo o curso", não se restringindo apenas às disciplinas de ES e de Práticas Educativas. "Todas as disciplinas [...] são teóricas e práticas. Num curso de formação de professores, todas as disciplinas de fundamentos e as didáticas 
devem contribuir para sua finalidade, que é formar professores" (PIMENTA; LIMA, 2004, p. 44).

Posto isto, reafirma-se a perspectiva de que "pensar em estágio é falar em projeto de curso, em formação específica e formação pedagógica, é tocar no calcanhar de Aquiles dos processos educativos: teoria e prática; conteúdo e forma; modos de produção do conhecimento [...]" (FERNANDES; SILVEIRA, 2007, p. 3), e isto transcende determinismos legais, transcende o próprio projeto formador de um curso.

$\mathrm{Na}$ Fase II das entrevistas, as estagiárias apontam referências teóricometodológicas para o ensino de música que, somadas às suas vivências no ES, estão promovendo uma visão diferenciada sobre a proposta curricular do curso de Licenciatura em Música, visto que estando inseridas em regência de classe nas escolas percebem carências advindas do curso, principalmente às referentes ao acentuado caráter teórico. "Conforme se vai crescendo dentro do curso e se começa o estágio, a gente vai percebendo mais a realidade de como é que funciona mesmo. A gente vê que a teoria é diferente da prática, muitas vežes". (ANDRÉIA, CE II - EG/2009).

Zeichner (2010) ressalta que

Um problema perene em programas de formação de professores mantidos por escolas superiores e universidades tradicionais tem sido a da falta de conexão entre os cursos de formação de professores dessas unidades e o campo da prática. Embora a maior parte dos programas universitários de formação de professores inclua agora múltiplos campos de experiência em toda sua extensão, e situem frequentemente as experiências de campo em algum tipo de parceria escola-universidade [...] a desconexão entre o que é ensinado aos estudantes nos cursos acadêmicos e suas oportunidades de aprendizagem para levar a termo tais práticas em suas respectivas escolas é, não raramente, muito grande [...]. (ZEICHNER, 2010, p. 483).

A despeito desta situação, parte das carências é narrada em superação pelas estagiárias, sobretudo após relatarem o próprio crescimento que tiveram desde a sua inserção no ES I.

Ao se realizar a análise das falas das licenciandas na ESE II, nota-se uma grande quantidade de menções aos trabalhos desenvolvidos como monitoras no Laboratório de Educação Musical (LEM/CE/UFSM) em flauta doce e no coro.

Com relação específica aos destaques de canto coral e de flauta doce como disciplinas significativas no processo de formação profissional, as licenciandas registram a atuação profissional dos professores que as ensinam no curso. Para elas, são modelos de bons professores, preocupam-se com os alunos, diversificam as formas de ensinar, discutem, são abertos ao diálogo, incentivando-as a progredirem nos estudos. 
Outro ponto destacado pelas entrevistadas foi o fato de ser uma turma pequena e com possibilidades de muitas discussões entre si. Como expressa Natália:

Eu acho que a nossa turma, somos nós três, então, é bom o trabalho. Tem uma troca. A gente discute tudo. A professora está junto também, então, tem uma troca bem bacana. Agora nos preocupamos com o todo. Antes, a gente se preocupava em dar aula e, às vezes, nem notava como é que estavam os alunos. (NATÁLIA, CE II - EG/2009).

Em cada aula acontece alguma coisa que não deu certo. Neste momento conversar com a supervisão é importante. A importância disso, porque termina uma aula, a gente vem pra cá conversar, já troca ideias. A gente não está sozinho. Faz um planejamento. É muito bom. 'Não sei se essa atividade vai funcionar tão bem com essa turma', dai vem a professora auxiliar, ajudar a repensar. É muito bom. A supervisão está sendo muito boa. (LUÍZA, CE II - EG/2009).

As ponderações sublinham que ser professor é uma atividade que requer formação acadêmico-profissional. Ninguém é professor apenas pensando em sê-lo. "Então, pensar em estágio é falar em projeto de curso, em currículo, em formação dita específica e formação pedagógica - a formação pedagógica não tem especificidade?" (FERNANDES, 2010, p. 329). Para que ocorra a docência é necessário que se tenha no mínimo uma tríade - professor/estudante/ conhecimentos - que deve ser pensada na relação instituição formadora e espaços de atuação profissional. As dinâmicas desta tríade e de seus espaços constitutivos é que permeiam os processos de ensinar e aprender. O que foi ressaltado pelas estagiárias com relação ao seu desenvolvimento no estágio, agora, já em fase final do ES II, foi o amadurecimento no processo de formação acadêmico-profissional.

$E u$, particularmente, o que tenho sentido mais ultimamente é o gosto por ensinar, gostar mesmo. É que agora a gente está vendo mais resultados dos trabalbos que a gente comecou. Eles já estão respondendo bem mais e estão realmente aprendendo. (NATÁLIA, CE II - EG/2009).

É essa segurança que com o tempo a gente vai adquirindo. Tendo o jogo de cintura, sabendo lidar com certas situações como as mais inesperadas. No início, eu tinha um pouco de receio de lidar com as crianças, mas agora melhorou muito. (ANDREIA, CE II - EG/2009).

$\mathrm{Na}$ segunda fase da pesquisa, observa-se que as estagiárias familiarizaramse com o desconhecido e passaram a compreender de modo diferente o significado do ES. Dentro deste contexto, o ES passa a ser visto como um espaço/lugar demarcatório para a construção docente. Braúna et al. (2011) destacam, a partir da perspectiva de alunas da Pedagogia de Viçosa (MG), o momento do ES como

[...] as experiências mais significativas da formação, favorecendo, ao longo do desenvolvimento do curso, a criação de um campo especial que Jodelet 
(2005) denomina de 'vivido', já que se refere a um cotidiano que retira a estudante do 'banco escolar' e a coloca com outros sujeitos, tendo que assumir posturas, atitudes, ações e reflexões próprias sobre os lugares de aprender [...] esse vivido é tanto uma invasão pela emoção, quanto um momento que toma consciência de sua subjetividade, de sua identidade. (BRAÚNA et al., 2011, p. 15368).

A terceira e última fase da pesquisa aconteceu no ano de 2010. As ESE III aconteceram nos meses de junho e julho de 2010, quando as estagiárias estavam iniciando o ES III e, em novembro, deu-se a EG, quando estavam finalizando o ES IV. As estagiárias, notadamente, continuam transformando suas ideias e crenças sobre o ES e a docência. Cada experiência e dilema vivido no ES bem como a referência a novas formas de se pensar e fazer o ensino ativam reconstruções nas representações sociais sobre o ES. Em consequência, ocorrem modificações com relação aos valores, às crenças de docência/ser professor. Ao longo do curso, as estagiárias estão desenvolvendo novos conhecimentos no campo da música, da educação musical e da educação, além de estarem imersas no ES e em discussão de suas práticas com a supervisão do estágio. Isto corrobora com a compreensão de que

Estágio não é atividade prática, mas teórica, instrumentalizadora da práxis docente, entendida esta como atividade de transformação da realidade. Nesse sentido, o estágio curricular é atividade teórica de conhecimento, fundamentação, diálogo e intervenção na realidade, esta, sim, objeto da práxis. (PIMENTA; LIMA, 2004, p. 45).

A soma do que as licenciandas vivem no curso é tomada como a causa das transformações dos valores, das crenças com relação ao ES, apoiando a compreensão de que a formação acadêmico-profissional possui relevância para a formação de professores de música, bem como de outras áreas.

Com relação à experiência docente e ao destaque do momento marcante no estágio, as estagiárias salientam:

Algo que me surpreendeu bastante foi uma das turmas que a gente foi observar e era muito difícil. Pedimos referências musicais para eles e só mencionaram conhecer aquelas músicas de rádio, com letras bem complicadas...não conbeciam nada de música infantil, de música feita para a faixa deles. Então, trabalhamos uma música do Pandorga da Lua com eles e foi muito bom! Pude perceber que as crianças são bem abertas, o que falta são outras escutas, vivencias com música. Isso para mim é marcante! (LUÍZA, CE III - ESE 2010).

Fiquei bem feliz quanto a professora C...veio falar comigo e com as demais colegas e disse que as professoras do Núcleo de Educação Infantil onde estagiamos comentaram que fomos excelentes estagiárias. Falaram da qualidade de nossos materiais, de nossas aulas. A gente recebeu este elogio...um momento marcante é isso, de saber que tu fez. um bom trabalho. (NATÁLIA, CE III - ESE 2010). 
Essa atitude de reconhecimento com relação ao trabalho das estagiárias demarca uma mudança expressiva em suas posturas, já que passam a acreditar mais em si, a buscar, na sua própria organização de conhecimentos e práticas, as referências para ensinar. Aquelas manifestações anteriores, que eram fortemente calcadas nos modelos dos professores e em educadores musicais, agora passam a ser adicionadas a uma postura de "eu posso". Com relação a isto, entende-se que

Será no confronto com as representações e as demandas sociais que a identidade construída durante o processo de formação será reconhecida, para o qual são necessários os conhecimentos e o compromisso profissional. Trata-se pois, de nos estágios se trabalhar a identidade em formação definida pelos saberes, e não ainda pelas atividades docentes. (PIMENTA; LIMA, 2004, p. 64).

Novamente, retoma-se a importância da formação acadêmicoprofissional para a formação de professores e a necessidade de que este espaço constitua-se em um lugar de vivencias teóricas e práticas amplas, problematizadas com relação à docência, a ser professor de música nos diferentes contextos da educação, escolares ou não.

Com relação específica ao $\mathrm{ES}$, a crença de que é preciso aplicar na prática o que foi aprendido parece estar superada. E no que diz respeito a como percebem o ES no início do último ano do curso, as estagiárias comentam:

No ES é dificil falar em facilidades (risos) até porque antes de dar aula no estágio eu nunca tinha atuado com prática pedagógica... então... não sei talvez. alguma facilidade eu tenha adquirido com os planejamentos das aulas...esse é um ponto que eu acho que eu sei fazer bem... mas o problema é colocar na prática. O estágio é muito importante para esse momento que você tem que parar e pensar, como eu vou ensinar o meu aluno? Se colocar no lugar do aluno, tentar entende-lo. E, ao mesmo tempo, a gente é um pouco, assim: é reflexo daquilo que os nossos professores nos orientam. Então tentar formar nossa identidade profissional nesse "meio de campo". (ANDRÉIA, CE III - ESE 2010).

Não, acho que não me tornei professora ainda. 'To' me construindo aos poucos. A gente vai mudando, vai sempre pensando. Como eu digo, a gente tem que estar sempre repensando a nossa prática. Mas ainda tenho pouca experiência para dizer que eu sou professora. Tenho realizado alguns estágios, algumas atividades como estagiária, como monitora, mas quero serprofessora! Acho que ainda não sou professora. Eu penso que o estágio contribuiu muito porque temos uma resposta muito direta dos alunos e, ao mesmo tempo, você tem uma orientação, que você pode estar trocando ideias, vendo onde você errou, onde você acertou, ou que poderia ter sido diferente. (LUIZA, CE III - ESE 2010).

Em penso que o ES é um momento de a gente aprender. É a primeira vez que eu estou dando aula para crianças de primeiro ano. O ano passado [referindo-se ao ES na EI) era uma coisa prazerosa que a gente gostava e esse semestre, tá sendo bem pesado. Eu continuo com a visão de que é pouco esses quatro semestres de estágio supervisionado. Fico imaginando como era antes que tinha apenas um semestre (espanto!). (NATÁLIA, CE III - ESE 2010). 
Percebe-se que é no entrelaçamento entre a formação na instituição e a prática do ES, em seus desafios na escola e em outra realidade, no comprometimento com o desenvolvimento dos estudantes que a constituição da docência vai acontecendo. Se antes a docência ia se constituindo em imagens de professores, agora traz para as estagiárias a sua própria docência.

O ES constitui-se na ação do licenciando em sua articulação com o curso de licenciatura em música (espaço no qual são construídos conhecimentos e vivências musicais, assim como representa local de discussão sobre a docência em música) e com a docência em música realizada em espaço de atuação profissional. Essa ação real é, ao mesmo tempo, objetiva e subjetiva. Objetiva porque implica o trabalho com conteúdos específicos de música, e subjetiva por produzir diversos sentidos e significados nos envolvidos (estagiários e alunos). Assim, o ES é constituído pelo "fazer", "pensar" e "sentir" do licenciando, mediados pelos aprendizados e vivências em música e na docência, construídos ao longo do curso de música e durante o espaço de atuação docente na escola (SOUZA, 2011). Pode-se entender que o ES constitui-se, assim, pela ação envolvida que um licenciando realiza internamente no curso e, externamente, com a docência em espaço de atuação profissional.

$\mathrm{Na}$ última fase das entrevistas, as estagiárias, que estavam terminando o ES IV, apontaram algumas questões relevantes e que modificam crenças iniciais em relação a este componente curricular e, em consequência, revelam outra visão com relação à docência e a ser professor. As decisões pessoais frente aos problemas/dilemas/conquistas na sala de aula aparecem muito ligadas à forma pela qual as estagiárias estão se colocando como professoras. Assim expressam:

É, isso é legal, a gente vai ganhando mais segurança, parece que aos poucos aquele ser professor vai mudando. (NATÁLIA, CE III, EG 2010).

A gente tem mais noção pra saber o que precisa mudar, o que a gente pode fazer pra tentar deixar melhor. Então, como a Natália falou, vai se construindo uma identidade. E chega a tal ponto que a gente já consegue identificar, pensar sobre as nossas próprias práticas. (ANDRÉIA, CE III, EG 2010).

É que a gente vai criando uma identidade, entendeu? Vai pegando um pouquinho de cada um: Ah! eu prefiro fazer assim, mas a outra pessoa prefere fazer de tal jeito. E eu acho que é um ano inteiro no Ipê e a gente segue uma regra. A gente não sabe como fazer, então vai seguir aquele modelo. Então, agora, no último semestre, por exemplo, se eu fizer um plano e não der certo, eu vou fazer outra coisa. (LUÍZA, CE III, EG 2010).

Dessa forma, vão se colocando com a ideia de que, agora, são um "modelo de nós mesmas para nós mesmas". O que se visualiza neste valor de construção docente é que o narrar-se está misturado com um processo formativo no qual as experiências de docência e a formação acadêmico-profissional estão 
sendo internalizadas e constituindo outras formas de ser das estagiárias. Modos de estar em estágio de forma mais aberta às necessárias mudanças que decorrem do movimento social no qual está a escola em que estagiam e também de suas realizações como alunas da licenciatura em Música.

Existe uma dissolução da crença de que a formação é um processo de aplicabilidade de teorias à prática, ao mesmo tempo em que se compreende a docência como um processo dinâmico de atuação profissional e contínuo na sua construção. Desse modo, as posições com relação ao ES no curso e ao seu desenvolvimento vão se somando e sendo discutidas com relação às percepções iniciais.

Com base no exposto, a representação sobre ensinar, ser professor de música, vai sendo transformada na busca da realização profissional que promova melhores condições de desenvolvimento dos alunos com a música.

\section{Algumas considerações: "o que estou procurando é meu jeito"}

Retomando o já exposto, na pesquisa, teve-se como objetivo estudar longitudinalmente, num período de três anos, as representações de um mesmo grupo de estagiárias do curso de Música - licenciatura (UFSM) acerca das ideias, dos valores, das crenças e das orientações que constituíam esse campo curricular na sua formação docente. Partiu-se do pressuposto de que, ao longo desse período, teorias de senso comum somadas à formação acadêmico-profissional universitária da licenciatura adicionavam-se para configurar as representações acerca do ES.

Neste momento, retomam-se os objetivos sem a pretensão/possibilidade de separá-los em momentos estanques, devido ao fato de que as representações de um sujeito (licenciandas/estagiárias) com relação a um objeto (estágio supervisionado/docência) estão vinculadas a um todo, decorrendo de um contínuo processo de construção e reconstrução da realidade pelo sujeito que as produz. Da mesma forma "parece lícito afirmar que, se de um lado buscamos os elementos mais estáveis, aqueles que permitem a emergência de identidades compartilhadas, de outro trabalhamos com o que há de diferente, diverso e contraditório no fluxo do discurso social" (SPINK, 2004, p. 306).

As representações que as licenciandas têm sobre o que significa estágio supervisionado em música, em diferentes etapas do curso de licenciatura em música, têm seus percursos individuais, mas trazem alguns pontos comuns. $\mathrm{Na}$ primeira e na segunda fase, as representações destacadas são as de que o estágio supervisionado é "aplicar na prática uma teoria" e em ter um "modelo do professor", o qual se produz pela imagem positiva ou negativa enquanto se está na condição de aluno. 
Inicialmente, revela-se uma visão utilitarista e funcionalista do conhecimento aprendido que deve ser aplicado na prática. Com isso, as ideias de docência das estagiárias, neste primeiro momento da pesquisa, delineavam-se por desenvolver/apreender conhecimentos no curso e aplicá-los na prática escolar, quando no ensino de música para estudantes.

Paradoxalmente, revelavam-se, nas narrativas, as lembranças de professores que as estagiárias haviam internalizado como modelos de docência a serem seguidos quando estivessem em exercício profissional, o que em nada reflete a aplicação da teoria na prática. Com relação a isso, tem-se que a relação com o ensinar das estagiárias, naquele momento, estava marchetada no que AlvesMazzotti (2008) nomina como "universos consensuais". Dito de outra forma, o fato de ensinar baseando-se num modelo de professor, ressaltando os seus aspectos positivos (ou negativos) é uma teoria de senso comum na formação de professores e carrega consigo o fato de que: "se deu certo comigo como aluno dará certo comigo como professor".

Dessa maneira, vai sendo compreendido, na visão das estagiárias da pesquisa, que a origem das representações sobre estágio supervisionado em música, em diferentes etapas do curso de licenciatura em música, está intrinsecamente associada a dois fatores (que se transformam ao longo do curso). De início, há as referências pré-formação acadêmico-profissional e, posteriormente, as referências passam a ser pessoalizadas, na busca de uma estruturação pessoal da docência. "O que eu estou procurando é o men jeito" (ANDRÉIA). Sobre este segundo ponto, a partir da metade da pesquisa, já se começou a perceber tais transformações.

$\mathrm{Na}$ formação de professores "as fontes pré-profissionais do saber ensinar" são relevantes na constituição da docência; sobretudo aquelas vinculadas à história de vida pessoal e familiar do futuro professor que são "reatualizadas e reutilizadas, de maneira reflexiva mas com grande convicção, na prática de seu ofício" (TARDIF; RAYMOND, 2003, p. 6). Bellochio (2010) sublinhou o fato de que essa compreensão é expressiva na constituição de ser professor de estagiárias de música. Esse ponto também demanda a compreensão do estágio supervisionado como uma atividade de vivência da prática docente enfatizada pela relação teoria e prática e, portanto, “[...] componente curricular e eixo central nos cursos de formação [...]” (PIMENTA; LIMA, 2004, p. 29).

Outro ponto que se pode observar acerca da origem das representações da docência mistura-se com os saberes do curso de licenciatura e com as experiências musicais e pedagógico-musicais que vão sendo construídas ao longo da graduação, demarcando a relação entre o pessoal e o social na constituição de representações. "O curso, o estágio, as aprendizagens das demais disciplinas e experiências e vivência dentro e fora da universidade ajudam a construir a identidade docente". (PIMENTA; LIMA, 2004, p. 67) 
Ao serem analisadas as crenças e as perspectivas das licenciandas na constituição representacional do que significa o estágio supervisionado em música e suas articulações com a educação musical na educação básica, nota-se o quanto o mundo da escola, no qual as estagiárias estavam vivendo a sua docência, demonstrava-se, a princípio, distante do mundo já vivido como aluna. A escola mudou para elas quando lhes provocou a sua atuação como estagiária (estudante), com saberes acadêmicos, mas, em muito, com exigências profissionais de ser professora (profissão).

Para as estagiárias, o ES em música ultrapassa o que pensavam ser a aula de música. A crença e a perspectiva quase que direta de que a aula de música seria realmente uma "aula de/com música", nas escolas de educação básica em que atuaram, foi gerando outros pontos de vista. Com crianças pequenas, a preocupação com o cuidar e o educar foram desafios constantes. Com estudantes dos anos iniciais, dar aula de música implicava buscar, em outras áreas, possíveis relações com o que gostariam de trabalhar.

As estagiárias, sobretudo na Fase 3 da pesquisa, consideraram que as escolas não estão equipadas com materiais necessários para as aulas de música, bem como não dispõem de espaço físico adequado para atividades sonorizadas, como são as de natureza musical. Expressões como "as turmas são agitadas", "não se consegue trabalhar com composição, apreciação, execução musical - tem muito pouca concentração na turma", "tem que ficar o tempo todo chamando a atenção dos alunos", "parece que não estou dando aula de música" foram referências recorrentes. Com relação a este ponto, pondera-se que

Se há, por um lado, o reconhecimento de que o estágio tanto é uma etapa importante na formação de professores, quanto uma oportunidade da maior relevância para estar em contato com a escola, há indícios razoavelmente claros de que a organização institucional na universidade é pouco coerente com a necessidade de convívio com a escola. A organização de horários e atividades não favorece a realização de um trabalho integrado e reitera, nesse sentido a linha divisória entre o trabalho feito nas duas instituições. Acaba se fazendo, sob certo modo, um trabalho paralelo. O problema dessa analogia geométrica é que duas linhas paralelas, em tese, nunca se encontram. (WIELEWICKI, 2010, p. 87).

Enfim, pode-se compreender que as transformações das crenças e ideias sobre o estágio supervisionado, ao longo da formação inicial de licenciandos em música, decorrem da ampla inserção das estagiárias em seu curso, participando como estudantes em disciplinas curriculares, mas também em outras atividades. Decorrem dos aprendizados internalizados em sua formação pré-profissional e também das reflexões realizadas quando em estágio nas escolas, desafiandose a fazer uma aula de música qualificada e que atinja interesses pessoais, da 
supervisão/orientação e da escola/espaço educativo. As representações, assim, vão sendo modificadas, mantendo alguns traços comuns, já que as estagiárias têm uma idade semelhante e convivem no mesmo grupo social, mesma turma de faculdade, amigos e colegas músicos, mas modificando outros, na medida em que cada uma tem a sua subjetividade e produz-se diferentemente em seu processo de desenvolvimento como futura professora de música.

Finalmente, entende-se que as representações das licenciandas, estagiárias em música, vão sendo modificadas ao longo da formação acadêmico-profissional e que o aspecto central trazido em relação à docência no ES carrega a aspiração positiva de ser uma boa professora de música nos diferentes espaços educativos.

\section{Referências}

ARRUDA, A. Teoria das representações sociais e teorias de gênero. Cadernos de Pesquisa, São Paulo, n. 117, p. 127-147, nov. 2002. DOI: 10.1590/S0100-15742002000300007

ALVES-MAZZOTTI, A. J. Representações Sociais: aspectos teóricos e aplicações à educação. Revista Múltiplas Leituras, São Paulo, v. 1, n. 1, p. 18-43, jan./jun. 2008.

AZEVEDO, M. C. C. Os saberes docentes na ação pedagógica dos estagiários em música: dois estudos de caso. 2007. 437 f. Tese (Doutorado em Música) - Universidade Federal do Rio Grande do Sul, Porto Alegre, 2007.

BARDIN, L. Análise de conteúdo. Lisboa: Edições 70, 1977.

BELLOCHIO, C. R.; BEINEKE, V. A prática educativa do estagiário de educação musical: relato de um caso. In: ENCONTRO REGIONAL DA ASSOCIAÇÃO BRASILEIRA DE EDUCAÇÃO MUSICAL, 8., 2005. Pelotas, Anais... Pelotas: ABEM, CD-ROM.

BELLOCHIO, C. R.; BEINEKE, V. A mobilização de conhecimentos práticos no estágio supervisionado: um estudo com estagiários de música da UFSM/RS e da UDESC/SC. Música Hodie, Goiás, v. 7, n. 2, p. 73-88, 2007.

BELLOCHIO, C. R. Representações de estágio supervisionado de licenciandas em música na construção da docência: um estudo na UFSM/RS. In: CONGRESSO DA ASSOCIAÇÃO BRASILEIRA DE EDUCAÇÃO MUSICAL, 19.; SIMPÓSIO PARANAENSE DE EDUCAÇÃO MUSICAL, 15., 2010, Goiania. Anais... Goiania: ABEM, 2010. p. 1-9.

BELLOCHIO, C. R.; GARBOSA, L. W. F. Educação musical na formação inicial e continuada de professores: projetos compartilhados do laboratório de educação musical - LEM - UFSM/ RS. Cadernos de Educação, Pelotas, n. 37, p. 247-272, set./dez. 2010.

BOGDAN, R.; BIKLEN, S. Investigação qualitativa em educação: uma introdução à teoria e aos métodos. Tradução de Maria João Alvarez, Sara Bahia dos Santos e Telmo Mourinho Baptista. Porto: Porto Editora Ltda, 1994. 
BRAÚNA, R. de C. de A.; et al. Representações sociais e experiência vivida: reflexões sobre a constituição de identidades profissionais de graduandas de Pedagogia da UFV. In: CONGRESSO NACIONAL DE EDUCAÇÃO - EDUCERE, 10.; CONGRESSO INTERNACIONAL DE REPRESENTAÇÕES SOCIAIS, SUBJETIVIDADE E EDUCAÇÃO, 1., 2011, Curitiba. Anais... Curitiba: PUC/PR, 2011. p. 15356-15371. Disponível em: <http://educere.bruc.com.br/CD2011/pdf/6184_3498.pdf> Acesso em: 20 de fev. 2011.

BUCHMANN, L. A construção da docência em música no estágio supervisionado: um estudo na UFSM. 2008. 151 f. Dissertação (Mestrado em Educação) - Universidade Federal de Santa Maria, Santa Maria, 2008.

CONSELHO NACIONAL DE EDUCAÇÃO. Conselho Pleno. Resolução CNE/CP 01/2002 e CNE/CP 02/2002. Institui Diretrizes Curriculares Nacionais para a Formação de Professores da Educação Básica, em Nível Superior, Curso de Licenciatura, de Graduação Plena. Diário Oficial da União, Brasília, Seção 1, p. 31, 9 abr. 2002.

DINIZ-PEREIRA, J. E. A formação acadêmico profissional: compartilhando responsabilidades entre universidades e escolas. In: EGGERT, E. et al. Trajetória e processos de ensinar e aprender: didática e formação de professores. Porto Alegre, EdiPUCRS, 2008. p. 253-266.

FERNANDES, C. B; SILVEIRA, D. Formação inicial de professores: desafios do estágio curricular supervisionado e territorialidade na licenciatura. In: REUNIÃO ANUAL DA ANPED, 30., 2007, Caxambu. Anais... Caxambu: ANPEd, 2007. CD-ROM. (GT 4 Didática).

FERNANDES, C. B. O espaço-tempo do estágio nos movimentos do Curso: interrogantes, desafios e a construção de territorialidades. Cadernos de Educação, Pelotas, v. 3, n. 37, p. 325-345, set./dez. 2010.

FREITAS, D. S. et al. (Org.). Caderno do II Seminário de Estágios Curriculares supervisionados... Santa Maria: Imprensa Universitária, 2005.

GARCIA, C. M. Formação de professores: para uma mudança educativa. Porto: Porto, 1995.

IMBERNÓN, F. Formação docente e profissional: formar-se para a mudança e a incerteza. 2. ed. São Paulo: Cortez, 1999.

JODELET, D. Representações sociais: um domínio em expansão. In: JODELET, D. (Org.). As representações sociais. Rio de Janeiro: Eduerj, 2001. p. 17-44.

KULKSAR, R. O estágio supervisionado como atividade integradora. In: PICONEZ, S. B. A prática de ensino e o estágio supervisionado. 11. ed. Campinas: Papirus, 2005. p. 63-74.

LIMA, M. S. L. et al. A hora de prática: reflexões sobre o estágio supervisionado e ação docente. 3. ed. Fortaleza: Edições Demócrito Rocha, 2004.

MATEIRO, T. Las prácticas de enseñanza en la formación inicial del professorado de música en Brasil: tres estudios de caso. 2003. 477 f. Tesis Doctoral (Doctorado en Filosofía y Ciencias de la Educación - Educación Musical) - Universidad del País Vasco, Bilbao (España), 2003. 
A prática de ensino em música: uma reflexão a partir de três experiências de estágio. In: ENCONTRO ANUAL DA ASSOCIAÇÃO BRASILEIRA DE EDUCAÇÃO MUSICAL, 11., 2002, Natal. Anais... Natal: ABEM, 2002b. p. 664-670.

MATEIRO, T.; TEO, M. Os relatórios de estágio dos alunos de musica como instrumento de análise dos processos de planejamento. Revista da ABEM, Porto Alegre, n. 9, p. 89-96, set. 2003.

NÓVOA, A. Os professores e suas histórias de vida. In: NÓVOA, A. (Org.). Vidas de professores. Portugal: Porto Editora, 1992. p. 11-30.

Formação de professores e profissão docente. In: NÓVOA, A. (Coord.). Os professores e a sua formação. Lisboa: Dom Quixote, 1995. p. 15-34.

PACHECO, J. O pensamento e a acção do professor. Porto: Porto Editora, 1995.

PÉREZ GÓMEZ, A. A formação de professores da licenciatura. Porto: Porto Editora, 1992.

PICONEZ, S. B. A prática de ensino e o estágio supervisionado. 11. ed. Campinas: Papirus, 2005.

PIMENTA, S. G. O estágio na formação de professores. Unidade teoria e prática? 2. ed. São Paulo: Cortez, 1995.

PIMENTA, S. G.; LIMA; M. S. Estágio e docência. São Paulo: Cortez, 2004.

SOUZA, Z. A. Estágio Supervisionado. Diário de Pesquisa, 2011. (documento pessoal).

SUBTIL, M. J. D. Formação dos licenciandos em Música: o estágio curricular em questão. In: ENCONTRO ANUAL DA ABEM, 16., 2007, Campo Grande. Anais... Campo Grande, 2007. p. 1-7.

SPINK, M. J. P. (Org.). O conhecimento no cotidiano: as representações sociais na perspectiva da psicologia social. São Paulo: Brasiliense, 2004.

SPINK, M. J. MENEGON, V. M. A pesquisa como prática discursiva: superando os horrores metodológicos. In: Práticas discursivas e produção de sentidos no cotidiano: aproximações teóricas e metodológicas. São Paulo: Cortez, 2000. p. 63-92.

TARDIF, M. T.; RAYMOND, D. Saberes, tempo e aprendizagem do trabalho no magistério. Educação \& Sociedade, Campinas, v. 21, n.73, p. 209-244, dez. 2003. DOI: 10.1590/S010173302000000400013

TOURINHO, I. “Atirei o pau no gato, mas o gato não morreu...” divertimento sobre estágio supervisionado. Revista da ABEM, Porto Alegre, n. 2, p. 35-52, jun. 1995.

UFSM. Universidade Federal de Santa Maria. Projeto Político Pedagógico do curso de música - licenciatura. UFSM, 2005.

WERLE, K. A música no estágio supervisionado da pedagogia: uma pesquisa com estagiárias da UFSM. 2010. 128 f. Dissertação (Mestrado em Educação) - Universidade Federal de Santa Maria, Santa Maria, 2010.

WIELEWICKI, H. G. Estágio curricular supervisionado: concepções de supervisão. In: FREITAS, D. S. et al. Caderno do II seminário sobre estágios curriculares supervisionado. Enfrentando desafios formativos. Santa Maria: Imprensa Universitária, Universidade Federal de Santa Maria, Programa de Pós-Graduação em Educação, 2005. p. 25-36. 
Prática de ensino e formação de professores: um estudo de caso sobre a relação universidade-escola em cursos de licenciatura. 2010. 282 f. Tese (Doutorado em Educação) Universidade Federal do Rio Grande do Sul, Porto Alegre, 2010.

WILLE, R. B. Estágio supervisionado: relatos de uma experiência. In: ENCONTRO ANUAL DA ABEM, 13., 2004, Rio de Janeiro. Anais... Rio de Janeiro: ABEM, 2004. CD-ROM.

ZEICHNER, K. Repensando as conexões entre a formação na universidade e as experiências de campo na formação de professores em faculdades e universidades. Educação, Santa Maria, v. 35, n. 3, p. 9- 12, set./dez. 2010.

Recebido em 15/05/2011

Versão final recebida em 13/10/2011

Aceito em 10/03/2012 